\title{
Aluminum Nitride Transition Layer for Power Electronics Applications Grown by Plasma-Enhanced Atomic Layer Deposition
}

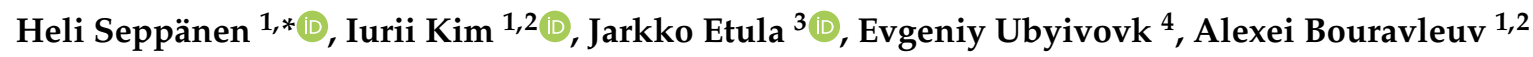 \\ and Harri Lipsanen ${ }^{1}$ \\ 1 Department of Electronics and Nanoengineering, Aalto University School of Electrical Engineering, P.O. Box \\ 13500, FI-00076 Aalto, Finland; iurii.kim@aalto.fi (I.K.); bour@mail.ioffe.ru (A.B.); \\ harri.lipsanen@aalto.fi (H.L.) \\ 2 St. Petersburg Academic State University, Ul. Khlopina 8/3, 194021 Saint Petersburg, Russia \\ 3 Department of Chemistry and Materials Science, Aalto University School of Chemical Engineering, P.O. Box \\ 16100, FI-00076 Aalto, Finland; jarkko.etula@aalto.fi \\ 4 ITMO University, Kronverksky pr. 49, 197101 Saint Petersburg, Russia; ubyivovk@gmail.com \\ * Correspondence: heli.seppanen@aalto.fi
}

Received: 30 November 2018; Accepted: 22 January 2019; Published: 28 January 2019

\begin{abstract}
Aluminum nitride (AIN) films have been grown using novel technological approaches based on plasma-enhanced atomic layer deposition (PEALD) and in situ atomic layer annealing (ALA). The growth of AlN layers was carried out on $\mathrm{Si}<100>$ and $\mathrm{Si}<111>$ substrates at low growth temperature. The investigation of crystalline quality of samples demonstrated that PEALD grown layers were polycrystalline, but ALA treatment improved their crystallinity. A thick polycrystalline AlN layer was successfully regrown by metal-organic chemical vapor deposition (MOCVD) on an AIN PEALD template. It opens up the new possibilities for the formation of nucleation layers with improved quality for subsequent growth of semiconductor nitride compounds.
\end{abstract}

Keywords: AlN; ALA; ALD; buffer layers; transition layer; MOCVD; regrowth

\section{Introduction}

III-nitrides including aluminum nitride (AlN) are attractive materials for high-power electronics, especially for high electron mobility transistors (HEMTs). The wide band-gap, high critical electric field, and high thermal conductivity of AlN provides an opportunity for HEMTs to withstand demands of aggressive environments [1]. Expensive bulk gallium nitride $(\mathrm{GaN})$ or AlN substrates enhance interest to growth of wide band-gap semiconductors on low-cost silicon $(\mathrm{Si})$, sapphire $\left(\mathrm{Al}_{2} \mathrm{O}_{3}\right)$ or silicon carbide ( $\mathrm{SiC}$ ) substrates [2-5]. Conventionally, III-N layers can be grown on $\mathrm{Si}$ substrates by metal-organic chemical vapor deposition (MOCVD) [6] or molecular-beam epitaxy (MBE). However, the high temperatures required for epitaxial growth, mismatches in the lattice and thermal expansion coefficient can result in the formation of numerous dislocations or even cracks in the GaN film on account of large tensile stress either during growth or during post-growth cooling $[7,8]$. The growth of AlN transition layer (TL) following by related buffer $\mathrm{Al}_{x} \mathrm{Ga}_{1-x} \mathrm{~N}$ layers are used between $\mathrm{Si}$ and $\mathrm{GaN}$ to overcome these issues [9-11]. Although the use of different step graded AlGaN and AlN buffer layers have been widely studied [12-17], the nucleation of the AlN layer on Si substrate is not well understood [18]. Moreover, the thick buffer layer is required to bury dislocations [19], which leads to an increase in the thickness of the device and inefficient consumption of materials.

One of the possible alternatives for thick buffer layers is use of thin AlN layer grown with plasma-enhanced atomic layer deposition (PEALD) [20]. Although it is commonly believed that atomic 
layer deposition (ALD) produces amorphous AlN film [21], the recently introduced in situ atomic layer annealing (ALA) [22] results in high-quality, hypothetically single-crystalline, AlN growth. Therefore, PEALD enables fabrication of low-cost templates with high quality AIN transition layer for following epitaxial steps of the device fabrication process. In the in situ ALA method, an extra plasma pulse with the plasma gas only is applied on the surface after each cycle, which provides extra energy for the bond formation and therefore enhances the crystallization process. Nevertheless, the properties of such ALA grown AlN films on different substrates have not been extensively studied previously. In the present work, the effect of $\mathrm{Si}<100>, \mathrm{Si}<111>$ substrates, as well as plasma treatment time and power on film growth are investigated.

\section{Results and Discussion}

The effect of the plasma treatment time and power on the film crystallization is shown in the grazing incidence X-ray diffraction (GIXRD) patterns in Figure 1. The increase of the intensity from (002) peak has previously been reported in literature [21-24] and indicates a hexagonal wurtzite aluminum nitride layer. Recently, Shih et al. [22] showed that the effect of ALA treatment results in epitaxial AlN film on sapphire. Figure 1 on the other hand shows also other orientations growing on $<100>$ silicon substrate. This can be explained by the differences between sapphire and silicon substrates. The hexagonal lattice of sapphire enables fully epitaxial growth of AlN in contrast with the cubic lattice of the silicon substrate.

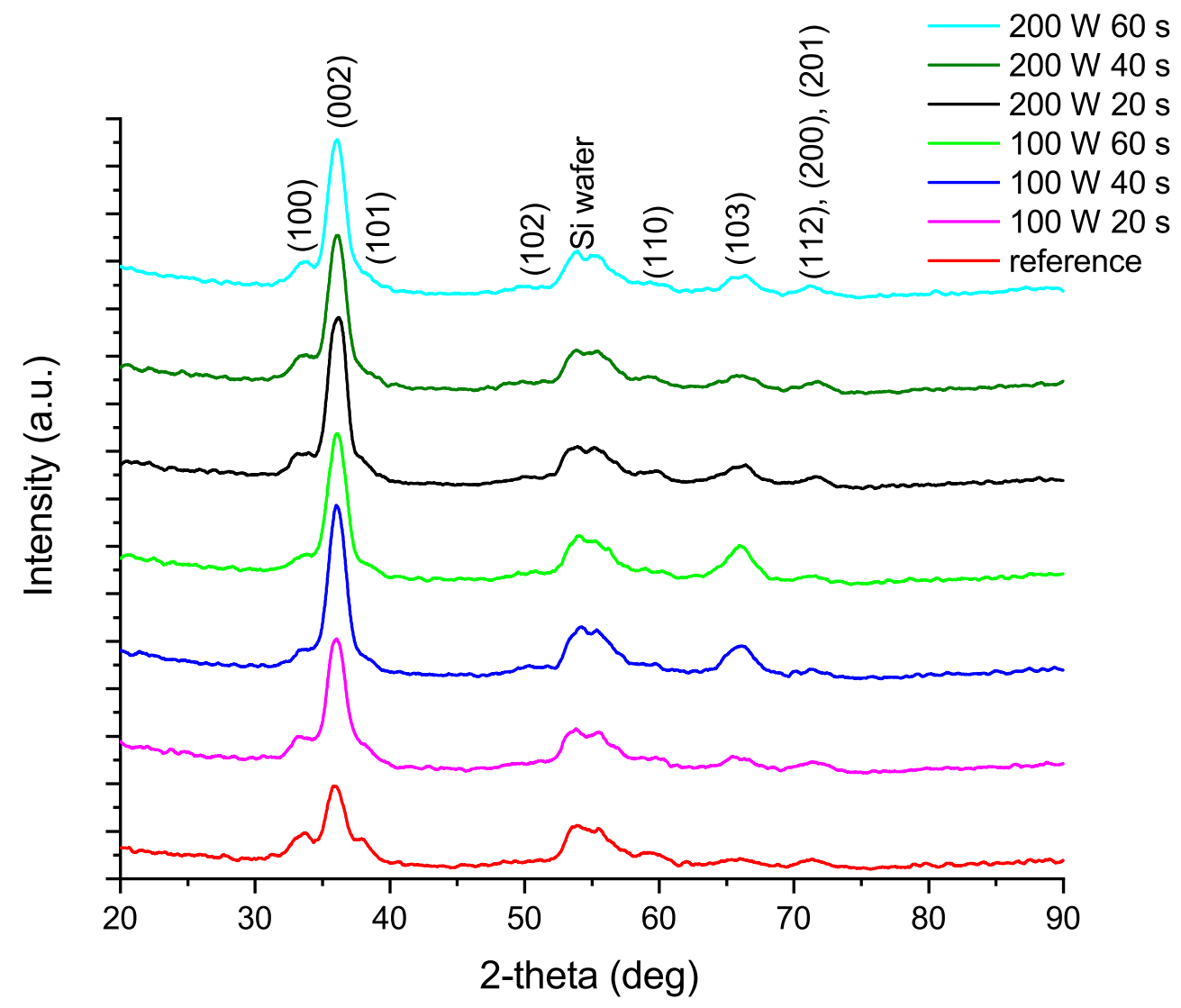

Figure 1. The 2-theta GIXRD patterns of the ALN layers on $\mathrm{Si}<100>$. Reference sample was grown without ALA treatment. The results are presented in the same order as in the legend.

The effect of the ALA treatment is already visible with only $100 \mathrm{~W}$ plasma power and $20 \mathrm{~s}$ treatment time. Compared to the reference sample without in situ ALA treatment (red line in Figure 1), the intensity increase of the (002) AlN peak is clear in all samples of the series. ALA treatment with $200 \mathrm{~W}$ plasma power for $60 \mathrm{~s}$ should provide sufficient energy to form the most epitaxial film due 
to surface heating [22]. Nevertheless, $200 \mathrm{~W}$ ALA treatment for $20 \mathrm{~s}$ already shows a comparably pronounced (002) peak. To decrease process times and costs, a shorter process of comparable result is often preferable. GIXRD provides a sensitive and facile measurement of thin film crystallinity without an interfering substrate background, but is less comprehensive in studying fully epitaxial films when compared to reciprocal space mapping.

The preference of (002) growth can be explained by the required energy to form $\mathrm{Al}$ and $\mathrm{N}$ bonds. The (002) plane in wurtzite lattice is formed by two bonds with different lengths. The longer bond requires lower energy and forms only the plane (100) or has no preferred orientation. The shorter bond requires higher energy to form. The planes (002) and (101) are formed only when both of the bond types exist in a well-formed order [25]. The formation of wurtzite lattice during deposition of AlN is explained in closer detail by Xu et al. [25] and Zhang et al. [26]. The formation of (100) plane can also be noticed when comparing the (100) peak from the reference sample to any of the ALA treated samples; the intensity of the (100) peak remains constant regardless of the applied plasma power or time. This demonstrates the substrate imitating nature of epitaxial ALD growth as the it takes place at the available surface sites and therefore automatically copies the surface structure. Subsequently the sufficient thermal energy from the plasma forms the preferred orientation of AlN. This effect is most evident when comparing the $100 \mathrm{~W} 20 \mathrm{~s}$ and $40 \mathrm{~s}$ ALA treated samples with the reference; the intensity of (100) remains constant as the intensity of (002) grows.

The $200 \mathrm{~W}$ and $60 \mathrm{~s}$ sample was further investigated with TEM. Figure 2 shows the TEM cross-section image of the interface between $\mathrm{Si}<100>$ and ALA treated AlN, where a thin about $3 \mathrm{~nm}$ epitaxial AlN layer is distinct at the interface. This epitaxial layer at the interface is further noticed from the GIXRD patterns from the corresponding (100) peak apparent in all of the measured samples. According to the TEM image, the microstructure of the film is polycrystalline. This is in agreement with the GIXRD results in Figure 1, and further suggests that shorter ALA process times of $20 \mathrm{~s}$ can be preferable. The thickness of the film is in accordance with the approximately $28 \mathrm{~nm}$ thickness obtained from both ellipsometry and X-ray reflectometry (XRR) shown in the Supplementary Information (Figure S1). Identical substrates with silicon dioxide layer on top of the bulk silicon were used for the matching of XRR data. The results from the matching are presented in Table 1.

The density from the XRR matching was $3.0 \mathrm{~g} / \mathrm{cm}^{3}$ which is quite close to the theoretical density $3.26 \mathrm{~g} / \mathrm{cm}^{3}$ of AlN [27]. The top layers of AlN seem less dense and are probably caused by surface oxidation in contact with air. This, as well as any alignment errors can affect the matching of the XRR data to simulation and hence density [28]. The growth of the ALA treated AlN was also investigated on less mismatched $\mathrm{Si}<111>$ substrate. The GIXRD patterns from the films are presented in Figure 3. Since the (002) peak is clearly pronounced in all of the samples in the plasma power and time series, the process with $200 \mathrm{~W}$ plasma power and $20 \mathrm{~s}$ ALA treatment was chosen for further investigation with other silicon substrates due to the fastest processing time and clear difference in crystallinity to the twin process with $100 \mathrm{~W}$ plasma power.

Table 1. Thickness, density and roughness from matching of XRR data of the ALA treated films on $\mathrm{Si}<100>$ substrate.

\begin{tabular}{|c|c|c|c|}
\hline Sample & Thickness (nm) & Density $\left(\mathrm{g} / \mathrm{cm}^{3}\right)$ & Roughness (nm) \\
\hline $100 \mathrm{~W} 20 \mathrm{~s}$ & 28.3 & 3.0 & 1.5 \\
\hline $100 \mathrm{~W} 40 \mathrm{~s}$ & 28.3 & 3.0 & 1.5 \\
\hline $100 \mathrm{~W} 60 \mathrm{~s}$ & 26.6 & 3.0 & 1.3 \\
\hline $200 \mathrm{~W} 20 \mathrm{~s}$ & 28.8 & 3.1 & 1.5 \\
\hline $200 \mathrm{~W} 40 \mathrm{~s}$ & 28.6 & 3.1 & 1.6 \\
\hline $200 \mathrm{~W} 60 \mathrm{~s}$ & 27.8 & 3.0 & 1.7 \\
\hline
\end{tabular}




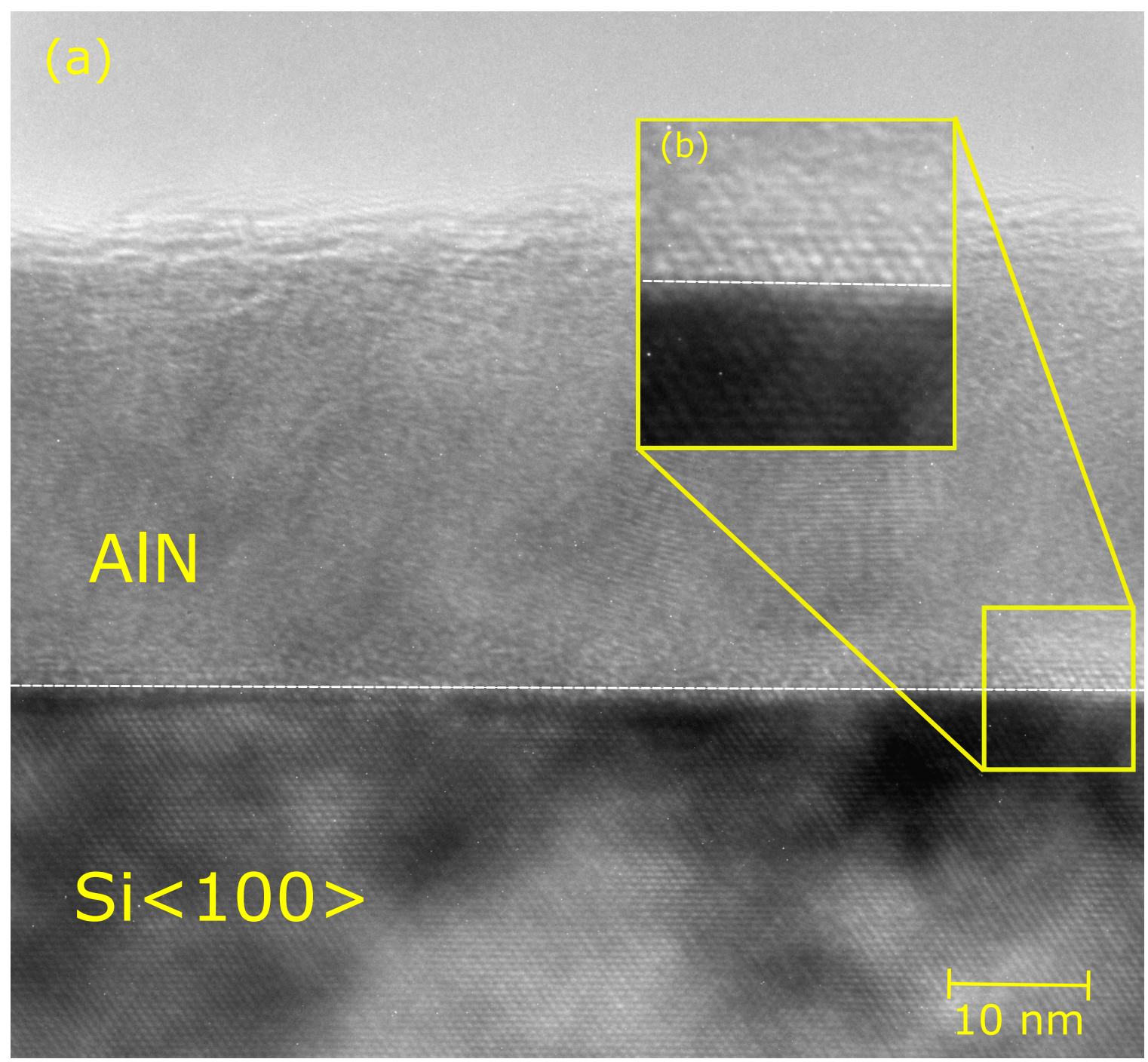

Figure 2. (a) TEM cross-section image of $30 \mathrm{~nm}$ AlN grown on $\mathrm{Si}<100>$ with a in situ ALA treatment at plasma power of $200 \mathrm{~W}$ and $60 \mathrm{~s}$; (b) Enlarged interface of the $\mathrm{Si}<100>$ substrate and AlN of the cross-section.

The effect of preferred growth of (002) plane is apparent on every substrate. Previous research [26] found the lattice of $\mathrm{Si}<111>$ to positively affect on the hexagonal AlN formation. The effect was also detected in this research as a higher intensity (002) peak from the $\mathrm{Si}<111>$ substrate compared to the peak from $\mathrm{Si}<100>$. The (100) peak, however, remains as high in both of the bare silicon substrates.

The proposed ALD AIN layer is suggested to act as the transition layer (TL) between substrate and further III-N layers e.g., in high-power applications. To demonstrate the general feasibility of ALA treatment method, we fabricated a sample with thick $(\sim 2 \mu \mathrm{m})$ AlN layer presented in Figure 4. 


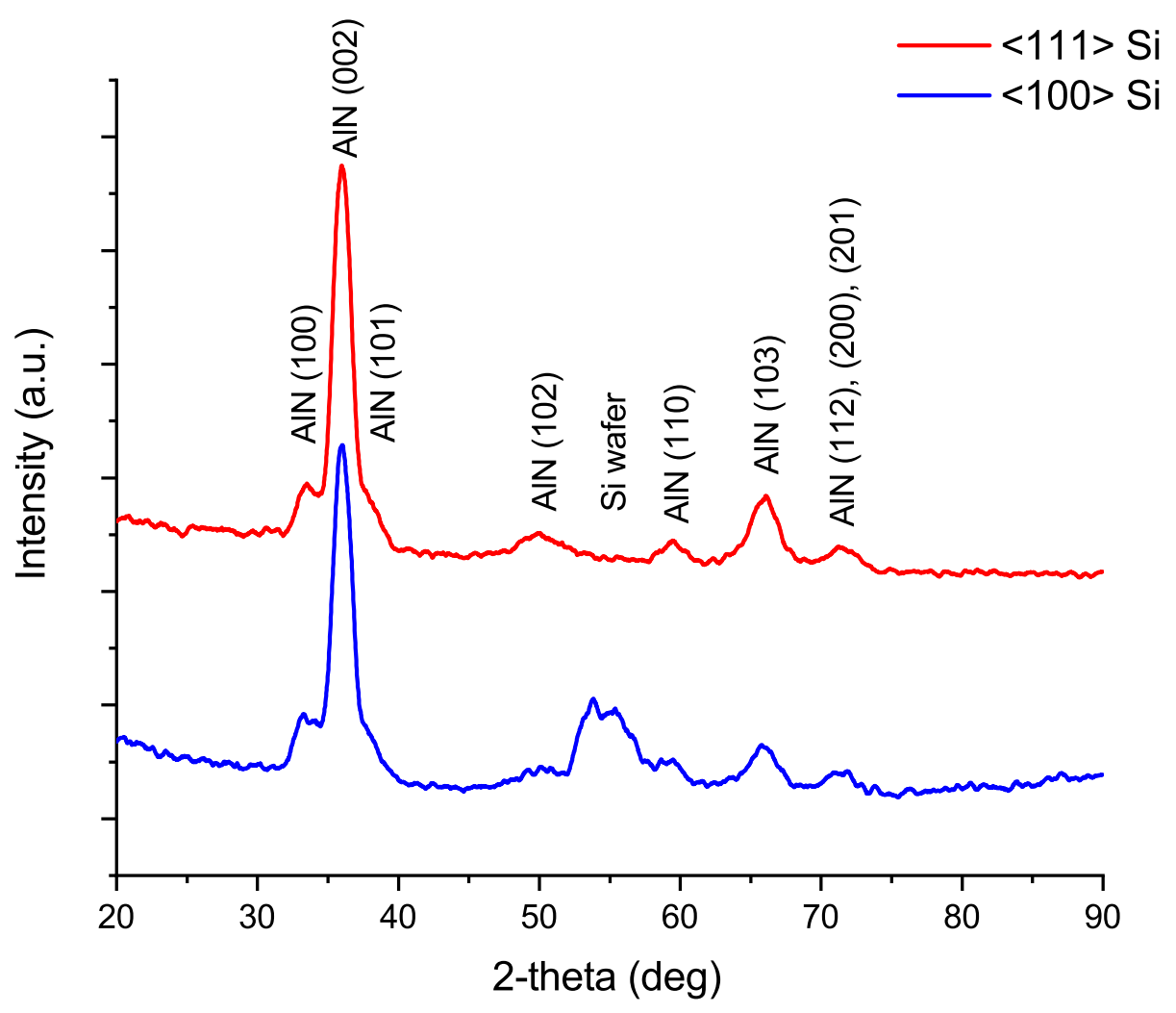

Figure 3. The 2-theta GIXRD patterns of $200 \mathrm{~W}$ and $20 \mathrm{~s}$ in situ ALA treated layers on $\mathrm{Si}<111>$ (top) and $\mathrm{Si}<100>$ (bottom).
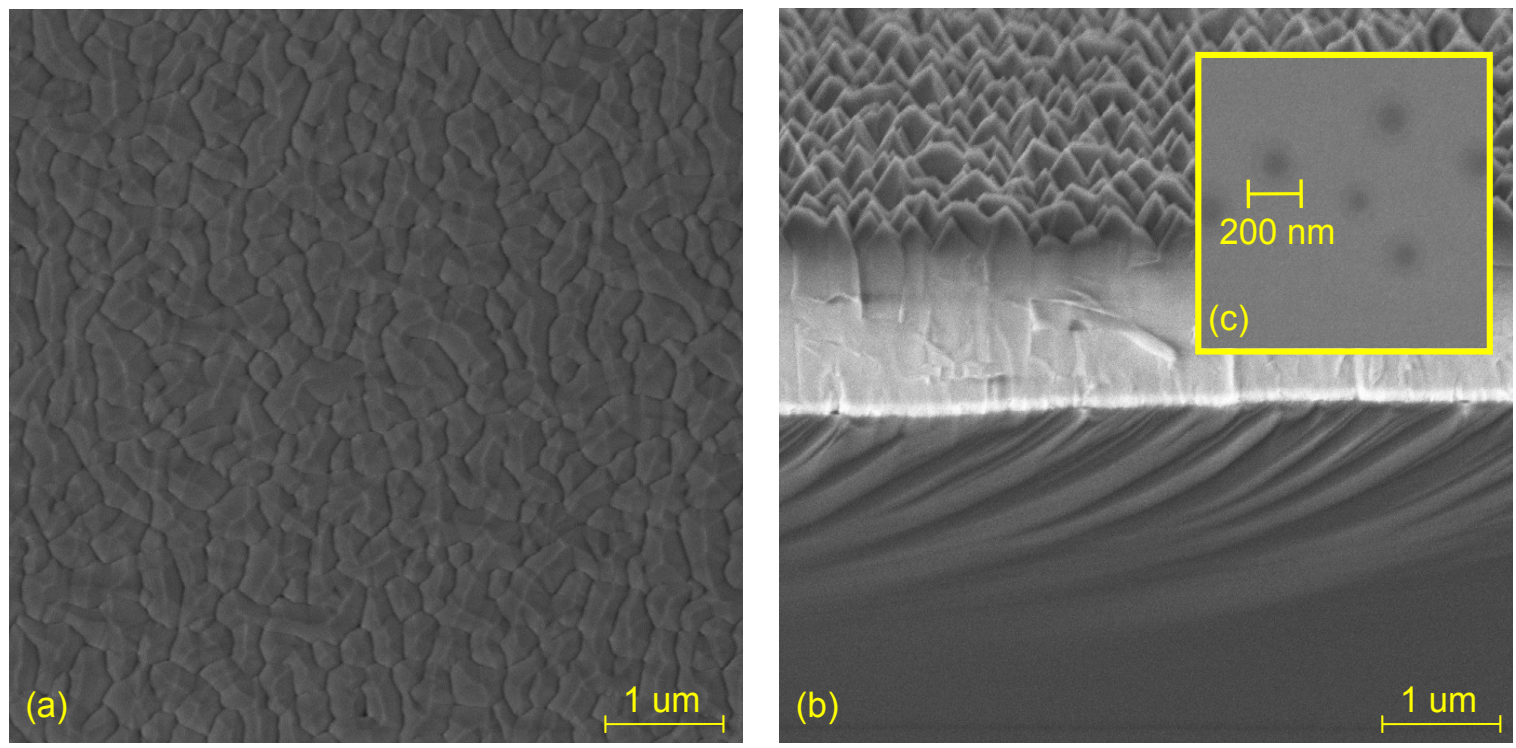

Figure 4. Top (a) and cross-sectional (b) SEM images of regrown AlN layer by MOCVD on top of ALD AlN transition layer (TL); (c) Top SEM image of blisters in the TL AIN grown on $\mathrm{Si}<100>$ with an in situ ALA treatment at plasma power of $100 \mathrm{~W}$ and $40 \mathrm{~s}$.

The $100 \mathrm{~W}$ and $40 \mathrm{~s}$ sample was used as a template for AIN MOCVD regrowth. Figure 4a shows a top scanning electron microscope (SEM) view of regrown AIN layer by MOCVD. The interfaces between AlN grains (dark strips), which are clearly seen in the image, allow us to deduce that the film has a columnar structure with an average diameter of $100 \mathrm{~nm}$. The cross-sectional view presented 
in Figure $4 \mathrm{~b}$ also reveals high roughness of the top layer. The high roughness is probably caused by the polycrystalline ALD film. Regrowth of MOCVD AlN film on top of the ALD AlN film was successful despite so-called blisters on the ALD layer surface presented in Figure 4c. They are probably caused by $\mathrm{H}_{2}$ vapor traps [29] due to insufficient purge times or poor flow geometry of the chamber. The $\theta-2 \theta$ XRD pattern of the regrown AIN by MOCVD on top of PEALD template is shown in the Supplementary Information (Figure S2). The peaks at (002), (101) and (004) define that AlN layer was polycrystallized. However, the surface quality and AlN crystallographic orientation of grown MOCVD layer should be further analyzed. Nevertheless, already this possibility for the regrowth clearly indicates the ALD AlN transition layer as a potential replacement for current thick buffer layers in III-N devices.

\section{Conclusions}

Highly (002) oriented AIN transition layer grown in PEALD with in situ ALA treatment was demonstrated. The effect of the plasma power and duration in the in situ ALA treatment was studied in more detail on $\mathrm{Si}<100>$. $\mathrm{Si}<111>$ was found to be the most promising of the silicon substrates, since the effect of the crystallization in the wanted (002) direction was distinct. This, however, should be further verified with reciprocal space mapping of the films. The effect of different ALA treatments crystallization preferring (002) direction on $\mathrm{Si}<111>$ remains for future studies. In addition, we demonstrated the use of AlN layer grown in PEALD as a transition layer for further MOCVD regrowth, indicating that PEALD with ALA treatment provides a viable pathway to fabricate III-N devices on silicon substrates.

\section{Materials and Methods}

Aluminum nitride was grown in a plasma-enhanced ALD reactor (TFS-500, Beneq Oy, Espoo, Finland). Trimethylaluminum (TMA) and ammonia $\left(\mathrm{NH}_{3}\right)$ were used as precursors and argon ( $\left.\mathrm{Ar}\right)$ as the carrier and plasma gas. The depositions were made at $300{ }^{\circ} \mathrm{C}$ based on the process presented by Bosund et al. [21] with $0.3 \mathrm{~s}$ and $3 \mathrm{~s}$ TMA pulse and purge times and $15 \mathrm{~s}$ and $5 \mathrm{~s} \mathrm{NH}$ pulse and purge times. The in situ ALA was varied from the reference $0 \mathrm{~s}$ to $20 \mathrm{~s}, 40 \mathrm{~s}$ and $60 \mathrm{~s}$ with plasma powers $100 \mathrm{~W}$ and $200 \mathrm{~W}$. ALA was performed directly after each ALD cycle with only Ar as plasma gas. The plasma power for the reference sample was $200 \mathrm{~W}$ for the $\mathrm{NH}_{3}$ pulse. The samples were cooled down in nitrogen $\left(\mathrm{N}_{2}\right)$ atmosphere after the deposition. The deposited thickness was around $28 \mathrm{~nm}$ and was verified with an ellipsometer (Plasmos SD2300, Philips Analytical Technology GmbH, Munich, Germany) right after the cool down. The crystallinity, thickness, density and roughness of the films were determined with XRR and GIXRD measurements using a Rigaku SmartLab diffractometer. Surface optimized grazing incidence XRD scans were measured in parallel beam mode at an incidence angle of $0.4^{\circ}$ using a $9 \mathrm{~kW}$ rotating anode with a germanium monochromator ( $\mathrm{Cu} \mathrm{K} \alpha_{1}$ radiation) and a 2D detector (HyPix-3000).

Supplementary Materials: The following are available online at http:/ /www.mdpi.com/1996-1944/12/3/406/s1, Figure S1: The measured XRR (red) and fitted (blue) curves from the plasma series and the reference sample, Figure S2: $\theta-2 \theta$ XRD scan of the regrown MOCVD AlN.

Author Contributions: Conceptualization, A.B. and H.L.; Formal analysis, H.S. and J.E.; Funding acquisition, H.L.; Investigation, H.S., I.K., J.E. and E.U.; Project administration, I.K.; Writing—original draft, H.S. and I.K.; Writing - review \& editing, H.S., I.K., J.E., A.B. and H.L.

Funding: This research received no external funding.

Acknowledgments: We acknowledge the provision of facilities and technical support by Aalto University at Micronova Nanofabrication Centre and OtaNano-Nanomicroscopy Center (Aalto-NMC). TEM studies were provided using the equipment of the Interdisciplinary Resource Centre for Nanotechnology of St. Petersburg State University. A.B. acknowledges funding from the Academy of Finland (Grant No. 276376). H.L. acknowledges funding from the Academy of Finland (Grant No. 298297).

Conflicts of Interest: The authors declare no conflict of interest. 


\section{References}

1. George, T.; Son, K.A.; Powers, R.A.; Del Castillo, L.Y.; Okojie, R. Harsh environment microtechnologies for NASA and terrestrial applications. Proc. IEEE Sens. 2005, 2005, 1253-1258. [CrossRef]

2. Millan, J.; Godignon, P.; Perpina, X.; Perez-Tomas, A.; Rebollo, J. A Survey of Wide Bandgap Power Semiconductor Devices. IEEE Trans. Power Electron. 2014, 29, 2155-2163. [CrossRef]

3. Paskova, T.; Hanser, D.A.; Evans, K.R. GaN Substrates for III-Nitride Devices. Proc. IEEE 2010, 98, 1324-1338. [CrossRef]

4. Baliga, B.J. Gallium nitride devices for power electronic applications. Semicond. Sci. Technol. 2013, $28,074011$. [CrossRef]

5. Ambacher, O. Growth and applications of Group III-nitrides. J. Phys. D Appl. Phys. 1998, 31, $2653-2710$. [CrossRef]

6. Thompson, A.G. MOCVD technology for semiconductors. Mater. Lett. 1997, 30, 255-263. [CrossRef]

7. Zhu, D.; Wallis, D.J.; Humphreys, C.J. Prospects of III-nitride optoelectronics grown on Si. Rep. Prog. Phys. 2013, 76, 106501. [CrossRef]

8. Figge, S.; Kröncke, H.; Hommel, D.; Epelbaum, B.M. Temperature dependence of the thermal expansion of AlN. Appl. Phys. Lett. 2009, 94, 101915. [CrossRef]

9. Kadir, A.; Srivastava, S.; Li, Z.; Lee, K.E.K.; Sasangka, W.A.; Gradecak, S.; Chua, S.J.; Fitzgerald, E.A. Influence of substrate nitridation on the threading dislocation density of GaN grown on $200 \mathrm{~mm} \mathrm{Si} \mathrm{(111)}$ substrate. Thin Solid Films 2018, 663, 73-78. [CrossRef]

10. Lemettinen, J.; Kauppinen, C.; Rudzinski, M.; Haapalinna, A.; Tuomi, T.O.; Suihkonen, S. MOVPE growth of $\mathrm{GaN}$ on 6-inch SOI-substrates: Effect of substrate parameters on layer quality and strain. Semicond. Sci. Technol. 2017, 32. [CrossRef]

11. Zolotukhin, D.; Nechaev, D.; Kuznetsova, N.; Ratnikov, V.; Rouvimov, S.; Jmerik, V.; Ivanov, S. Control of stress and threading dislocation density in the thick GaN/AlN buffer layers grown on Si (111) substrates by low- temperature MBE. J. Phys. Conf. Ser. 2016, 741, 012025. [CrossRef]

12. Amano, H.; Sawaki, N.; Akasaki, I.; Toyoda, Y. Metalorganic vapor phase epitaxial growth of a high quality GaN film using an AlN buffer layer. Appl. Phys. Lett. 1986, 48, 353-355. [CrossRef]

13. Lang, T.; Odnoblyudov, M.; Bougrov, V.; Suihkonen, S.; Sopanen, M.; Lipsanen, H. Morphology optimization of MOCVD-grown GaN nucleation layers by the multistep technique. J. Cryst. Growth 2006, 292, $26-32$. [CrossRef]

14. Lang, T.; Odnoblyudov, M.A.; Bougrov, V.E.; Suihkonen, S.; Svensk, O.; Törmä, P.T.; Sopanen, M.; Lipsanen, $\mathrm{H}$. Reduction of threading dislocation density in $\mathrm{A} 10.12 \mathrm{Ga} 0.88 \mathrm{~N}$ epilayers by a multistep technique. J. Cryst. Growth 2007, 298, 276-280. [CrossRef]

15. Yang, Y.; Xiang, P.; Liu, M.; Chen, W.; He, Z.; Han, X.; Ni, Y.; Yang, F.; Yao, Y.; Wu, Z.; et al. Effect of compositionally graded $\mathrm{AlGaN}$ buffer layer grown by different functions of trimethylaluminum flow rates on the properties of $\mathrm{GaN}$ on $\mathrm{Si}$ (111) substrates. J. Cryst. Growth 2013, 376, 23-27. [CrossRef]

16. Lemettinen, J.; Okumura, H.; Kim, I.; Rudzinski, M.; Grzonka, J.; Palacios, T.; Suihkonen, S. MOVPE growth of nitrogen- and aluminum-polar AlN on $4 \mathrm{H}-\mathrm{SiC}$. J. Cryst. Growth 2018, 487, 50-56. [CrossRef]

17. Pan, L.; Dong, X.; Li, Z.; Luo, W.; Ni, J. Influence of the AlN nucleation layer on the properties of AlGaN/GaN heterostructure on Si (1 111$)$ substrates. Appl. Surf. Sci. 2018, 447, 512-517. [CrossRef]

18. Le Louarn, A.; Vézian, S.; Semond, F.; Massies, J. AlN buffer layer growth for GaN epitaxy on (111) Si: Al or N first? J. Cryst. Growth 2009, 311, 3278-3284. [CrossRef]

19. Davis, R.; Einfeldt, S.; Preble, E.; Roskowski, A.; Reitmeier, Z.; Miraglia, P. Gallium nitride and related materials: Challenges in materials processing. Acta Mater. 2003, 51, 5961-5979. [CrossRef]

20. Liu, X.; Ramanathan, S.; Lee, E.; Seidel, T.E. Atomic Layer Deposition of Aluminum Nitride Thin films from Trimethyl Aluminum (TMA) and Ammonia. MRS Proc. 2004, 811. [CrossRef]

21. Bosund, M.; Sajavaara, T.; Laitinen, M.; Huhtio, T.; Putkonen, M.; Airaksinen, V.M.; Lipsanen, H. Properties of AlN grown by plasma enhanced atomic layer deposition. Appl. Surf. Sci. 2011, 257, 7827-7830. [CrossRef]

22. Shih, H.Y.; Lee, W.H.; Kao, W.C.; Chuang, Y.C.; Lin, R.M.; Lin, H.C.; Shiojiri, M.; Chen, M.J. Low-temperature atomic layer epitaxy of AlN ultrathin films by layer-by-layer, in-situ atomic layer annealing. Sci. Rep. 2017, 7, 1-8. [CrossRef] 
23. Rontu, V.; Sippola, P.; Broas, M.; Ross, G.; Sajavaara, T.; Lipsanen, H.; Paulasto-Kröckel, M.; Franssila, S. Atomic layer deposition of AlN from $\mathrm{AlCl} 3$ using $\mathrm{NH} 3$ and $\mathrm{Ar} / \mathrm{NH} 3$ plasma. J. Vacuum Sci. Technol. A 2018, 36, 021508. [CrossRef]

24. Liu, S.; Peng, M.; Hou, C.; He, Y.; Li, M.; Zheng, X. PEALD-Grown Crystalline AlN Films on Si (100) with Sharp Interface and Good Uniformity. Nanoscale Res. Lett. 2017, 12, 279. [CrossRef]

25. Xu, X.H.; Wu, H.S.; Zhang, C.J.; Jin, Z.H. Morphological properties of AlN piezoelectric thin films deposited by DC reactive magnetron sputtering. Thin Solid Films 2001, 388, 62-67. [CrossRef]

26. Zhang, J.; Cheng, H.; Chen, Y.Z.; Uddin, A.; Yuan, S.; Geng, S.J.; Zhang, S. Growth of AlN films on Si (100) and $\mathrm{Si}$ (111) substrates by reactive magnetron sputtering. Surf. Coat. Technol. 2005, 198, 68-73. [CrossRef]

27. Slack, G. Nonmetallic crystals with high thermal conductivity. Surf. Coat. Technol. 1973, 34, 321-335. [CrossRef]

28. Windover, D.; Gil, D.L.; Azuma, Y.; Fujimoto, T. Determining sample alignment in X-ray reflectometry using thickness and density from GaAs/AlAs multilayer certified reference materials. Meas. Sci. Technol. 2014, 25, 105007. [CrossRef]

29. Broas, M.; Jiang, H.; Graff, A.; Sajavaara, T.; Vuorinen, V.; Paulasto-Kröckel, M. Blistering mechanisms of atomic-layer-deposited $\mathrm{AlN}$ and $\mathrm{Al}_{2} \mathrm{O}_{3}$ films. Appl. Phys. Lett. 2017, 111. [CrossRef]

(C) 2019 by the authors. Licensee MDPI, Basel, Switzerland. This article is an open access article distributed under the terms and conditions of the Creative Commons Attribution (CC BY) license (http:/ / creativecommons.org/licenses/by/4.0/). 